\title{
Understanding Information Related Fields: A Conceptual Framework
}

\author{
Ping Zhang \\ School of Information Studies, Syracuse University, Syracuse, NY 13244. E-mail: pzhang@syr.edu \\ Robert I. Benjamin \\ School of Information Studies, Syracuse University, Syracuse, NY 13244. E-mail: ribenjamin@cox.net
}

\begin{abstract}
Many scientific fields share common interests for research and education. Yet, very often, these fields do not communicate to each other and are unaware of the work in other fields. Understanding the commonalities and differences among related fields can broaden our understanding of the interested phenomena from various perspectives, better utilize resources, enhance collaboration, and eventually move the related fields forward together.

In this article, we present a conceptual framework, namely the Information-Model or I-model, to describe various aspects of information related fields. We consider this a timely effort in light of the evolutions of several information related fields and a set of questions related to the identities of these fields. It is especially timely in defining the newly formed Information Field from a community of twenty some information schools. We posit that the information related fields are built on a number of other fields but with their own unique foci and concerns. That is, core components from other fundamental fields interact and integrate with each other to form dynamic and interesting information related fields that all have to do with information, technology, people, and organization/society. The conceptual framework can have a number of uses. Besides providing a unified view of these related fields, it can be used to examine old case studies, recent research projects, educational programs and curricula concerns, as well as to illustrate the commonalities and differences with the information related fields.
\end{abstract}

\section{Introduction}

Information and communication technology (ICT) has penetrated in every part of our lives and our societies, and transformed the ways we think, feel, and act. Correspondingly, many scientific fields have evolved and/or emerged

Received April 27, 2006; revised October 1, 2006; accepted January 10, 2007

(C) 2007 Wiley Periodicals, Inc. • Published online 3 August 2007 in Wiley InterScience (www.interscience.wiley.com). DOI: 10.1002/asi.20660 over the decades, and continue to evolve in addressing new phenomena aroused by the fast changes in ICT development and adoption.

A notably newly formed field over the past decades is the information field (or I-field) that is composed of a community of information-schools (or I-schools; see Appendix for a list of these I-schools). The community brings together perspectives and approaches whose origins are in multiple and diverse fields such as library science, information science, computer science, linguistics, communications, management and business, management information systems, law, policy and public administration, human-computer interaction, psychology, among others. A significant phenomenon is that most of these I-schools have adopted the use of Information in their school names. Another significant phenomenon is that a good number of scholars who are trained or gained reputations in other fields are attracted to and are moving to the I-community as their physical and academic institutions. The information field is becoming more formalized, as demonstrated by the annual conferences of the I-community (the first was hosted by Penn State University in September 2005, the second by University of Michigan in October 2006, and the third to be by UCLA in October 2007).

A field of study has its intrinsic research interests and agendas as well as educational missions. While facing related fields such as library science, information science, management information systems, human-computer interaction, communications, among other fields that have all been evolving over the past decades, one would naturally ask: What is the I-field? What are the similarities and differences between the I-field and those just mentioned fields? What are the fundamental elements of concerns and issues of the I-field? What potential directions can the I-field take for research efforts, education missions, and practice? What opportunities can the I-field have for collaborations with other related fields? Such questions are also applicable to other related fields as well, as scholars who have been immersed in an inter- and multidisciplinary environment will recognize. 
Unfortunately, many fields normally do not communicate to each other and do not consciously share the inherent intellectual foundations (Ellis, Allen, \& Wilson, 1999; Zhang \& Dillon, 2003). Few studies have attempted to examine related fields in a systematic way.

In searching for answers to the previous questions, there is a need for developing a general framework that can depict the fundamental elements and concerns of the I-field as well as depicting other information related fields. This will help identify what the I-field is about and better understand the commonalities and differences among these closely related fields without neglecting or threatening their legitimacy and uniqueness. The framework should be robust, and should hold for a long enough period of time so that it can act as a guide to understand the past and present, and shed light on the potential future development of these several related fields. The framework should also be able to function as an equilibrium model to demonstrate the dynamic nature of a field. The framework is thus for people with different disciplinary perspectives to understand and appreciate research, education, and collaborative opportunities in the I-field and other related fields.

The advantages of examining these related fields are numerous. A clear understanding helps

- potential students at all levels to choose their desired study programs,

- educators to better serve both the students and the society at large,

- education administrators to find niches and leverages for new programs and initiatives,

- scholars to choose an academic environment that they feel most appreciative and comfortable,

- researchers to appreciate and collaborate with colleagues in other fields that share similar interests,

- policy makers to better utilize resources in guiding practice,

- recruiters from companies and agencies to better understand the potential fit of graduates to the companies' needs, and

- scholars to work together to advance all related fields.

In this article, we attempt to develop this framework in order to address at least some of the questions raised early in this section on what the I-field is about. We believe that the key that holds several fields as being related to each other as well as depicts the uniqueness of the I-field is the concept and phenomena of Information that has a social purpose. We will first present the framework we call the I-model with its essentials and its importance and values. We then illustrate the explanatory and prescriptive power of the I-model by demonstrating its potential uses in a number of areas: (a) to reanalyze specific research issues that are well studied in the literature as cases, (b) to reframe current research projects and studies, (c) to synthesize and suggest curricula issues in the information related fields, and finally (d) to depict relationships among several information related fields. Overall, we hope that the I-model not only illustrates the past and present of these fields but also helps project the potential future directions for the information related fields for research, education, practice, and collaboration.

\section{The Information Model (I-Model)}

The concept of information has many underpinning meanings and perspectives, depending on in which fields it is studied and in what context it is used. In general, information is related to concepts such as fact, data, knowledge, intelligence, news, communication, instruction, representation, mental experience, or stimulus, among others. Weaver supported a tripartite analysis of information (Weaver, 1949, in Floridi, 2005) in terms of (a) technical problems concerning the quantification of information and dealt with Shannon's information theory (Shannon, 1948), (b) semantic problems relating to meaning and truth, and (c) influential problems concerning the impact and effectiveness of information on human behaviors (Floridi, 2005). Without getting into the debate on what information is (which is beyond the scope of this article), we take primarily the view that information is semantic and influential. That is, information has meanings, purposes, and abilities to transform. In other words, we are concerned with information that has social purposes.

Taking this view of information can guide the identification of a number of fields that can be regarded as information related fields that have to do with information creation, representation, storage and retrieval, management, use, and transmission in social contexts. To name just a few examples, information science is about the storage and retrieval of recorded information; library science is the acquisition, cataloging, classification, and preservation of library materials to serve society's information needs; education is the teaching and learning of human knowledge; communication is about the processes of sharing information between senders and receivers; management information systems is about applying information and communication technology to support managerial and organizational decision making and problem solving; and journalism is about collecting, analyzing, verifying and presenting news regarding events, trends, issues and people.

We take the perspective that these information related fields share something in common, that is, they are all interdisciplinary and each of them presents an interaction, integration, and an equilibrium state of several components that are the core elements in some traditional fields. These components function as the pillars or foundations and thus are central to all of these information related fields. Therefore, we call them fundamental components (which will be discussed in detail next). Various interactions and integrations among the fundamental components define programs of study and research agendas in the information related fields. Different emphasis on one or more of these fundamental components can lead to distinctive research interests and educational concerns. Changes of equilibrium states indicate the adaptations of the elements and the evolution of the field over time in reaction to changes in itself and in its environment. 


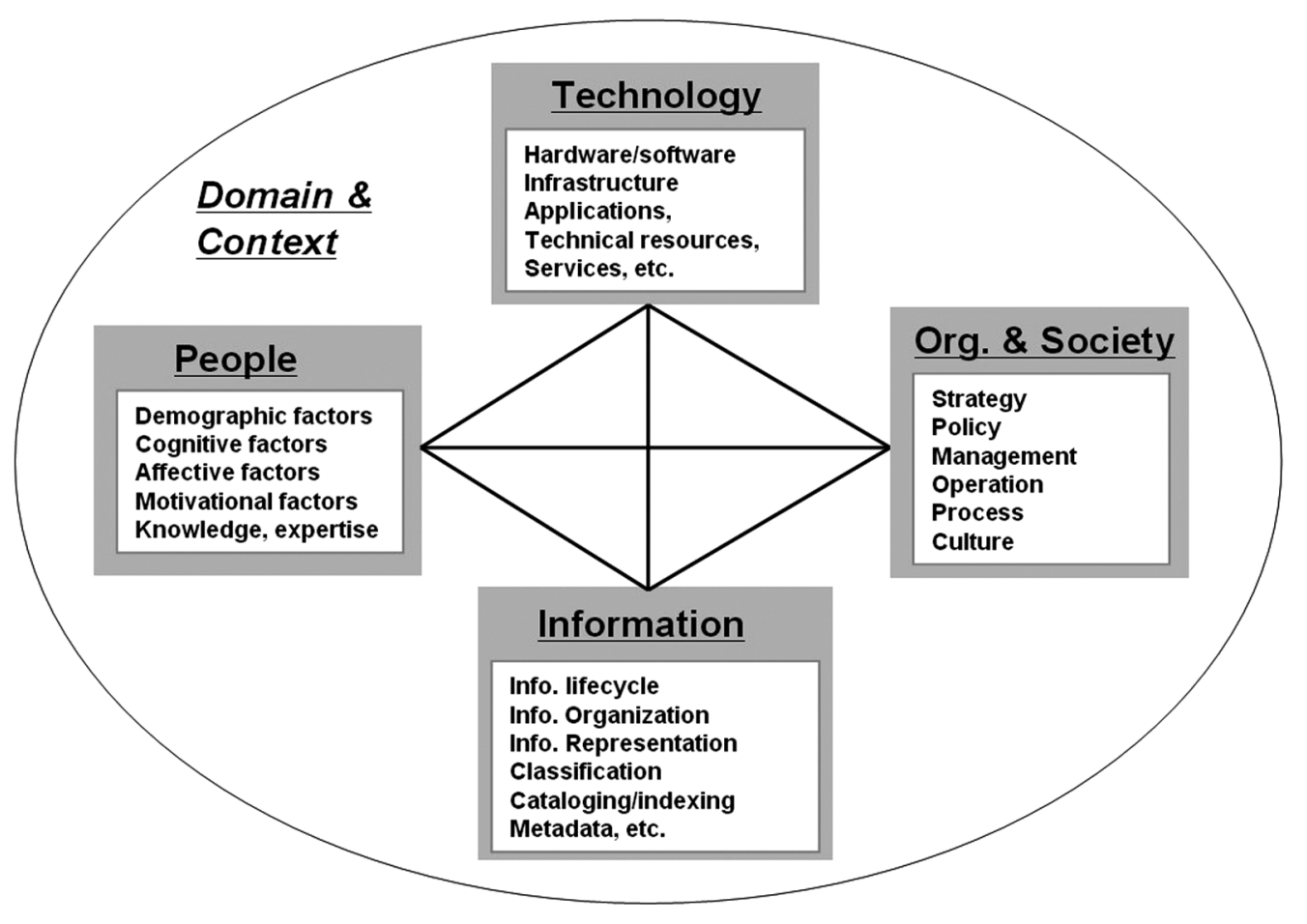

FIG 1. The information model.

Figure 1 depicts the essential idea of the Information Model (I-Model). It asserts that information with the help of technology can provide capabilities to people and to society in various domains and contexts. Next, we first describe the four fundamental components. Then we discuss the interaction, integration, and equilibrium states of these fundamental components. We further introduce other important elements, domain and context, in order to demonstrate the richness of the information related fields. We point out the social implications of the information related fields that can be studied by the I-model.

\section{The Fundamental Components of the Information Related Fields}

A component of a field is the object of scientific inquiry. A field of study can have many components. Some are more basic and fundamental; others can be dependent and less centric to all related issues. A fundamental component of a field is essential, exists independent of other components, and is concerned with the core of the field.

In the past, a three-component view of the information field was presented, implying three fundamental components, Information, People, and Information Technology, by a number of scholars in various occasions (for example, Dan Atkins from Michigan, John M. Carroll from Penn State, and Ray von Dran from Syracuse). Some of the ideas of this three-component view were presented in a report for future directions for the library profession and its education (Blackman et al., 1995). In a slightly different way, Ron
Larsen from Pittsburgh presented a three-component model that consists of Information, Technology, and Society (Larson, 2004, 2005). Benjamin and Levinson presented a similar three-component model of the management information systems (MIS) field (Benjamin \& Levinson, 1993). While arguing the inadequacy of existing paradigms for investigating complex sociotechnical systems, Linstone suggested to use multiple perspectives that consist of technical/analytical, organizational/societal, and personal/ individual (Linstone, 1985). Wood-Harper and Wood provided a good review of the past, present, and future of the social informatics approach pioneered by Rob Kling to address information and communication technology development (Wood-Harper \& Wood, 2005).

We believe that owing to the nature of the information related fields, there should be four fundamental components that these fields all possess: Information, Technology, People, and Organization/Society. This is a broader view than the early ones. Each of these four components has been a focal interest in other fields for a long time. For example, (a) information is a subject of study before information and communication technologies were invented and has been extensively studied in library science and information science, (b) technology is the core of computer science and engineering, (c) people is what psychologists, sociologists, and cultural anthropologists are interested in, and (d) organization or society is the interest of many social sciences.

Information with social purposes has a lifecycle that includes information being acquired or created, processed, disseminated, and used. Information is the object of main 
interests in the information related fields. Information has intrinsic characteristics that have been studied over decades in fields such as library science and information science. For example, information organization, form, structure, classification, cataloging, and indexing, among other topics (see Figure 1) are about the intrinsic nature of information. Applications of information in practice depend on how it interacts with other fundamental components and within what domains and contexts.

Technology is a general term that includes information and communication technology (ICT) as well as other types of technologies. Technology is the core of several fields including computer science, engineering, and telecommunications, among others. Normally the concept of technology refers to hardware, software, infrastructure, applications, resources, services, and the like. Technology-based information processing, communication, and information service are hallmarks of what we do in the digital world, and thus differ from (a) the traditional library science where ICT was not necessarily involved and (b) pure technical fields where technology is the core concern (although information is also concerned in computer science and electronic engineering but from a technological perspective rather than the social perspective). In the information related fields, we are interested in those technological aspects that are closely related to the activities during information's life cycle.

People are the fundamental drive for any advancement in science and technology. The information related fields are interested in people in ways that may differ from that of a psychologist or physician. Researchers are normally concerned with the aspects of people that may influence their information related skills, the ways they create, comprehend, use and disseminate information, and how they adapt to changes driven by the other factors. People include those who are users of ICT, who are designers and inventors of ICT, and those who manage and influence ICT use behaviors in various contexts. Figure 1 lists some aspects pertinent to studying people in the information related fields.

Organization and Society are human gatherings at different levels who share certain values, beliefs, goals, institutions, and processes. They can be classified as informal or formal, by structure (working groups, departments, businesses, nations and societies) or by purpose (industry sectors, nonprofit organizations, governments, etc.). In general, this component can be seen in one or more of these forms: working groups, organizations and institutions, communities, industries, governments, and global societies. Several important attributes that have been studied in the information related fields are of concern at all these levels: policy, strategy, management, operation, process, structure, and culture.

There are several other components of the information related fields that have been the objects of scientific inquiry. For example, researchers have also studied issues related to resources and their management, among others. To keep the I-Model parsimonious, we focus primarily on the fundamental components of the information related fields and refer to other components when necessary.
Interaction and Integration of the Fundamental Components

The information related fields are also about the various ways the fundamental components interact and integrate with each other. Interaction indicates mutual and reciprocal action or influence. Interactions among the fundamental components give them new meanings and significance in relation to each other. For example, information becomes meaningless without considering who and what it is for; technology loses its relevance without considering its information processing and manipulating purposes.

A specific set of interactions that form a research program or an education program can be thought of as an integration of the fundamental components. The concept of integration means to form, coordinate, or blend into a functioning or unified whole (Merriam-Webster online dictionary). Different research and education programs can be depicted as instances of the fundamental components at different levels of integration intensity. For example, information visualization reflects a strong technology component and moderate integration with the information and people components; social informatics suggests strong societal, people, and information components but less so with the technology component.

The interactions and integrations among the fundamental components can generate many interesting and exciting research streams as well as educational programs that can be of great interest to the information related fields and communities at large. For example, strong integration between information and technology can lead to research interests in information architecture, digital reference service, to name a few. By strongly integrating the people and organization/society components, the research areas can expand to IT implementation and change management in organizations, among others. Figure 1 depicts the idea of interaction and integration by the lines that connect the four components.

The studies of the fundamental components and their various interactions and integrations are inherently and intrinsically interdisciplinary; thus, it is normal for information related fields to be multidisciplinary and composed of scholars trained in many different traditional fields.

\section{Dynamic Qualities of the I-Model}

No scientific field can be static; it always faces environmental and internal changes thus the need to adapt. For example, when national security becomes a top priority in the United States national policy making, several scientific fields quickly adapted to the needs for research, practice, and education. Computer security, information security, and information assurance, among several others, become hot areas for training, research, and development. In order to represent such dynamic nature of scientific fields, the I-model should have the ability to be viewed from a dynamic perspective, and thus functions as an equilibrium model. 
Our biological system is a good example of an equilibrium model. When a test shows that the amount of red blood cells is within the normal range for a healthy human being, it is an indication that the many components of the human physiological system are in balance. We refer to this as stasis or equilibrium. When the red blood count moves outside of the normal range, it is a sign that the biological system is out of equilibrium. The system must be restored to its previous form of equilibrium, to a new form of equilibrium where its components will adapt differently to each other, or it will degenerate. This is so with all dynamic systems. People and organizations as an equilibrium process were described in the organizational behavior literature (Kegan \& Lahey, 2000; Schein, 1993, 1996) and in the MIS literature (Benjamin \& Levinson, 1993; Scott Morton, 1991). The information related fields are no exception for being equilibrium systems.

Effective changes in the information related fields require mutual adaptations among the fundamental components. In a real world that is full of uncertainties and changes, the likelihood is that the four fundamental components will reach a new state of equilibrium through nondirected mutual adaptation rather than a desired state through directed mutual adaptation. For example, when information technology achieved the capability to transform bits beyond text into pictures, communicating information on a screen required adaptations among information representations, technology, people, and organizations. Several additional examples can illustrate the dynamic nature of the model and the need for mutual adaptation.

- Alfred Chandler, in "The Visible Hand," (Chandler, 1977) describes the mutual adaptations over several decades between the strategy and the structure of enterprises necessary for the evolution of the multi-divisional form of organization. Improvements in transportation, the invention of the high-speed electronic accounting machines, and rapid spread of telephone technology were all changes that stimulated these adaptations.

- Jack Rockart (Benjamin, 1971; Dickson \& DeSanctis, 2001, pp. 2-12) described the eras of management information systems evolution in terms of the rapid changes in information technology, from main frames to mini computers to personal computers and to the Internet, as a movement from main-frame centric to finally network centric computing with adaptations in types of applications and governance required.

- Thomas Friedman in his book, "The World is Flat," (Friedman, 2005) explains how the changes in technology cost and performance have resulted in a wired world that has enabled adaptations in economically second-tier countries, enabling them to compete effectively with first-tier countries, such as the US and Japan.

Because the information related fields are dynamic, the I-model is intended to reflect changes within its fundamental components and the possible adaptation among the components. As technology advances and as different domain issues come to the fore, new programs of research can become important. Examples include the balance between privacy and security, the balance between intellectual property protection and fair use, and collaboration across organizational boundaries. Effective research requires understanding the changing relationships of the four fundamental components as they move from stasis to disequilibrium towards a new stasis. Effective research also requires setting appropriate domain and contextual constraints for the issue at hand. Studying the movement from stasis to disequilibrium and the accommodations necessary to return to a new form of stasis provides fruitful opportunities for research in such widely different research programs, such as medical informatics and enterprise architectures.

Taking such a dynamic interplay and mutual adaptation perspective provides us with a lens for viewing the past, current, and future interests in the information related fields for research, education, and practice.

\section{Domain and Context for Studies in the Information Related Fields}

Besides the four fundamental components, two additional components, domain and context, play important roles in information related fields and are thus worth mentioning. The concept of domain can have different meanings depending on where and how the term is used. In this article, we focus on two meanings to illustrate the characteristics of the I-model: (a) Domain can be synonymy of subject discipline or field of study, that is, subject domain; and (b) domain refers to the kinds of purposes for which ICT applications are carried out, that is, application domain. Subject domain plays an important role in library science and information science research where it is argued that domain-specifics should drive information indexing and retrieval studies and practice (Bates, 1998), and domain analysis is key to the entire information science field (Hjorland \& Albrechtsen, 1995). Subject domains, thus, are very important especially for information about infor-mation (or meta-information) type of research (such as those conducted in library science and information science).

For the second meaning, application domains normally provide the background and implied goals for ICT applications that address particular information related issues. For example, we can think of the business domain where commerce is conducted and profit is the goal. We can also think about hospitals, manufacturers, libraries, schools, governments, etc., as examples of application domains. The information related issues can carry domain specific characteristics. For example, information can be studied for business decision making purposes, for physicians to diagnose or treat patients, for librarians to function as intermediaries to help patrons, for government officials to make national policies, etc. There can be many contextual choices for researchers within a particular application domain. For example, the choice of people in a particular research area may be based on domain specific applications and issues. In the business domain, people issues can be related to customer relationship management, supply chain management, executives' decision making, or 
employees' daily routine information tasks. In the medical domain, people issues can be related to physician-patient relationship, physician information seeking, and use behaviors, patients, and patients' privacy concerns, etc.

It is useful to consider the connection and difference between subject domain and application domain. Very often, a subject domain implies an application domain. For example, the business field is concerned with various issues occurring in the business application domain. There are, however, many situations where one application domain could correspond to many subject domains. For example, the hospital domain corresponds to the fields of medicine, nursing, management, etc. A field (subject domain) can find applications in many application domains. For example, organization studies (as a field) can be applied to any application domain where there is a concern of human gathering with shared values or processes, including those in the library, hospital, hotel, business domains.

The term context is another widely used one with many meanings (e.g., a detailed discussion of this term can be found in Dervin, 1997; there is a series of conferences on information seeking in context). Without getting into the unnecessary debate of its definitions, in this article, we consider contexts as specific settings, circumstances, or conditions in which studies are conducted or practices are carried out. For example, a research study may be conducted in IBM's assembly facility in Austin, Texas. Although it is in the manufacturing domain, the specific organization and its local setting would put specific characteristics on the study and its results. In professional practice, context is significant. General rules or principles may have to be modified in a particular setting to incorporate the local core values, norms, constrains, opportunities, etc. This context concept is similar to the locality concept in information ecologies (Nardi \& O'Day, 1999).

Contexts play an important role in research. A particular context specifies which fundamental components come into play at which abstract level and how they interact and integrate with each other. For example, in a study on information technology (IT) use in emergency room operations, IT can be quite low fidelity (a white board) (Osterlund, 2000). People concerned in the study are doctors and nurses who have knowledge and expertise not only about the application domain (medical) but also about the particular context (the emergency room where they work). Other people involved may be patients and their families and relatives. Information is pertinent to the functioning of the emergency room. An emergency room is a working group (for the organization component) that has its own policies, strategies, structures, managerial, and operational issues, as well as its culture. All these components interact and integrate to form a particular unit to be studied.

By considering the interaction and integration of the four fundamental components in various domains and contexts, the information related fields can be considered with a multiplicity of possible research and education programs and education venues to meet emerging needs. For example, the integration of information, people, and technology in the legal, biological, and hospital subject domains would yield legal informatics, bioinformatics, and medical informatics programs, which are all educational programs in high demand in recent years.

\section{Societal Implications}

Unintended consequences of technologies and other artifacts can be a serious societal risk (Benjamin \& Eriksson, 2001; Brown \& Duguid, 2001; Joy, 2000). We generally refer to nth order effects of technology as unintended consequences. They can be positive, negative, or both, depending on a person's point of view. Historically, the nth order effects of a technology can be compelling. For example, the automobile created the modern highway system, the move to suburbia and exurbia, and the concentration of incredible rich and power in the oil-producing regions of the world. The ever-increasing power of technology, especially information technology, rapidly increases the risk of these unintended consequences with serious potential consequences for society. Bringing an intentional focus on unintended consequences related to technology is a grave challenge for the information related fields. The I-Model is intended to provide a venue for searching for unintended consequences, especially during the process of disequilibrium and reequilibrium.

Nardi and O'Day argue that local implementation can be developed from both a humane and ecological point of view (Nardi \& O'Day, 1999). From our perspective, their localized information ecologies are detailed instances of practice tested implementations of restricted version of the I-Model.

\section{The Potential Uses of the I-Model}

In this section, we point out four potential uses of the I-Model. The detailed explanations and analyses of these uses are beyond the scope of this article and will be reported elsewhere (e.g., in Liu, Benjamin, \& Zhang, 2007).

\section{Using the I-Model to Reexamine Historical Cases}

The I-Model can provide a framework to analyze past, current, and proposed future research in the information related fields. One interesting part is the potential power of the I-Model to reinterpret past research. We anticipate that the I-Model can reveal certain aspects on some past research that were not revealed before.

We demonstrate this use of the I-Model by using one example of research on management of IT enabled change. There is a large collection of articles and research studies about the subject of IT enabled change (Markus, 2003; Markus \& Benjamin, 1997). They reflect a relationship between several to all of the components depicted in the I-model. A famous case describes an early implementation of Zuboff's informated model, The Expense Tracking System 
at Tiger Creek (Zuboff, 1989; Zuboff \& Bronsema, 1984). In the case, once an automated system was implemented, workers had access to all the information necessary to do their jobs and they were empowered to perform tasks previously done by their supervisors. The case discusses how different actors (managers and workers) in the factory setting (paper mills) dealt with the change in power relationships as information technology changed the command and control system in the factory and moved from a traditional bureaucratic model to an informated model (Benjamin \& Levinson, 1993).

We can see how all the fundamental components come into play, and in a dynamic way:

Technology: The technology was a new infrastructure with certain hardware and software, which was built as the open information system with functions that included data collection, data analysis, and human computer interaction. The new technology totally changed the previous system and provided possible accessibility of information for all types of people in the mill.

Information: The information aspect is about the changes in representation of information, levels of information produced, and the ability to experiment with information and its effects on operations. The change was from information gained by sensory touch (finger in the paper pulp) and after-the-fact efficiency reports to real time numbers on screens that operators had to translate. The changes in information representation thus produced two different feedback loops involving different sensory stimuli and different time cycles for reaction. This idea of feedback of information is the same as Bates (1999) pointed out that is so commonly used in today's language yet is really an application of Weiner's cybernetic theory (Weiner, 1961, in Bates 1999).

People: The people included workers, operators, and executives. The focus was the effect of the new technology and the new control system on all levels of management from workers to executives. For example, for operators, the change was from being told what to do to being told to interpret the data and then take actions. Left on their own, operators on the unsupervised midnight shift would test out different operational variables in real time on the paper machines to see what produced the greater efficiency. The new information system influenced the beliefs and behaviors of people at different levels of the hierarchy. People's beliefs and behaviors also became the critical factor in determining the success or failure of the new information system.

Society/Organization: The involved organizations were the paper mills in a large paper conglomerate. They were the central factors to choose the management system, which pushed the innovation of technology and information. The organizational and managerial decisions made influenced the relationships between people and technology as well as people and information in this case.

The examination of the case using the I-model demonstrates the transitions of different fundamental components from one state to another as well as the consequences of such transitions on other components. Together, the transformations in these fundamental components searched for equilibrium and eventually reached one. In the Tiger Creek case, the new technology can be regarded as the initial force, which stimulated adaptations in all fundamental components. Technology itself was not enough to solve all the organizational problems and optimize the equilibrium. In the case, the people component was the most decisive component, which played the vital role on the implementation of IT enabled change. The examination of the case using the I-model draws several conclusions that are consistent with the literature on IT change management:

- Introduction of a new technology requires adaptations in all the fundamental components.

- Adaptation is difficult when the information produced by the technology is different in form and reaction time is required.

- Adaptation is difficult when the technology change affects the control system and power relationships of the organization.

- People are the most decisive component in a number of adaptations.

- Change only settles in when people have institutionalized the adaptations.

- Managerial resistance, from the people component, tends to undermine the change efforts, and gains are seldom fully realized. Organizations must establish strategy and policy that support the knowledge, information and power shift, as well as minimize the resistance.

In reexamining this case, the I-model is shown to be effective to trace the changes of states as the case unfolds, to visualize the dynamic in-depth relationships among different components, to analyze transformations among equilibrium states, and to compare related cases by using the same structure. Detailed application of the I-model to the Tiger Creek case can be found in (Liu et al., 2007). The explanatory power of the I-Model on existing research issues and cases need to be tested further.

\section{Using the I-Model to Examine Current Research Studies}

The discussion of the I-Model with several colleagues brings up the value of using the I-Model to function as a research tool. Many research studies in the information related fields are conducted focusing on some fundamental components without conscious awareness of or simply overlooking the other components. Bringing back the other fundamental components into the big picture and making them explicit may reveal some interesting aspects that were missing or prompt future research directions. From this perspective, the I-Model has a role in guiding research efforts and hopefully improving the quality of research. To illustrate this potential use of the I-model, we examine one recent research study on individual reactions toward ICT use (Zhang, Li, \& Sun, 2006). The study is a representation of a stream of research in the MIS field.

Zhang, Li, and Sun's study (Zhang et al., 2006) extended Agarwal and Karahanna's work (2000) on cognitive absorption and its role on individual technology acceptance. Agarwal and Karahanna suggested that holistic user experiences 
with IT contribute to users' evaluation of and reaction to using the technology. They proposed and empirically tested a construct named cognitive absorption (CA) that has preceding effects on important user technology acceptance constructs, such as cognitive beliefs (perceived usefulness, PU, and perceived ease of use, PEOU), and intention to use a target technology. Zhang et al. (2006) proposed that an important antecedent of cognitive absorption is perceived affective quality (PAQ) of the target IT. Such perception is a user's impression on the IT itself prior to any other cognitive appraisals on the consequences or potential interactions with the IT. Rooted in psychological work on affect and cognition, Zhang et al. developed a theoretical model that depicts the causal relationships among PAQ, cognitive absorption, cognitive beliefs, and IT use intention. A field study was conducted to validate this model. The results indicated that PAQ is a strong antecedent to cognitive absorption, explaining 39\% variances in it, and has direct impacts on cognitive beliefs.

Using the I-model, we can reveal the following from the Zhang et al. study:

- The application domain of the study was intended to be general. The study was conducted in a particular application domain (high education) and in a particular context (Syracuse University). It was about students (people) using Syracuse University Web site (technology) to obtain academic and other related information about the university (information).

- The study primarily focused on the interaction between the people component and the combination of the technology and information components. It is hypothesized that a student's subjective appraisal of the Web site's PAQ may determine his or her self-reported cognitive absorption with the Web site, and consequently, her cognitive appraisals and Web site use intention.

- In the study, the social or organizational component was implied. Students' use of the university website is considered voluntary. Besides considering Syracuse University students' reactions toward the university Web site (a fixed context), there were few organization/society factors taken into consideration in the study.

Although any particular study would have to define a manageable scope with an intended research focus, the following question may reveal some interesting potentials or future directions of a research stream: What would happen if other fundamental components are considered in the study? For example, would perceived affective quality still have a strong effect on cognitive absorption and other technology acceptance variables if organization component is one of the major factors in the study? In many cases, such as in situations where technology is Enterprise Resource Planning systems, users are faced with not only information and various information representations, but also embedded organizational processes, norms, routines, practices etc., that can be either empowering or disempowering. In such cases, are the perceived affective quality and cognitive absorption measurements modified by the social effects of the implementation on the individual? For example an ERP system can change the power relationships of a manager who now has access to a unified set of information within the organization, and that power may be more important than others that were studied such as cognitive absorption and perceived ease of use.

The Zhang et al. (2006) study is on the static view of a particular moment. The I-model suggests a dynamic adaptation among the components. This suggests possible research efforts on examining the dynamic or changing roles of PAQ and CA over time: What if people are getting used to some information and technology? Would the relationship among people and (information + technology) change in some way? What if management puts some intervention on the technology use (that is, the organization component comes into play in a study), would that change the relationship between people and (information + technology)?

Note that this analysis is not intended to take away the very useful line of work displayed in current studies but rather to demonstrate that (a) some interesting (and difficult) questions still remain to be answered, (b) these questions can be addressed in a relatively structured way by examining the research in terms of the four fundamental components and their interactions and adaptations, and (c) established research results may be challenged on whether they would hold if the other fundamental components are allowed to vary.

\section{Using the I-Model to Examine Curricula and Educational Programs}

The interactions, integrations, and dynamic adaptations among the fundamental components in various domains and contexts can generate many interesting and exciting research streams as well as educational programs. For example, a heavy interaction between information and technology can lead to research interests in information architecture, information visualization, information storage and retrieval, digital library, digital reference service, information systems design and evaluation, to name a few. Considering the many different organization and society needs as well as information use or application domains, there are areas such as bioinformatics, legal informatics, medical or health informatics, economics of information, public policy and information, information literacy, etc.

The I-Model can provide a structure to examine current curricula concerns and prescribe future educational programs. To illustrate, issues related to security are currently of great interest in the academy and practice. Considering security from the perspective of the I-Model, the curricula require a broad view of the organizational component particularly with respect to organizational culture and change management to the information component (e.g., information representation), the people component (beliefs and behaviors), as well as a host of difficult technology issues to be confronted. This is important to realize and take actions upon, because current study indicates a skewed and over 
emphasis on the technology component in security education (Stanton \& Stam, 2006).

\section{Using the I-Model as a Generic Framework for Several Information Related Fields}

Going back to the opening of the article, we now use the I-Model to illustrate the similarities and differences among several information related fields, specifically, library science, information science, MIS, and HCI. It is to be noted that these fields are used as examples to illustrate the utility of the I-model. They do not represent all or only information related fields. It is also noted that different disciplines may have different perspectives and underpinning meanings of information, thus leading them to differ from each other. We will discuss this during this section.

Library science is the study of all aspects of library functions. It covers such topics as selection and acquisition policy, classification systems, and cataloguing, as well as bibliography and administration (Crystal, 2001). Information Science is about the collection, classification, storage, retrieval, and distribution of recorded information or knowledge, e.g., on computers or in library (Allen, 2000). Information science investigates the properties and behavior of information, the forces governing the flow of information, and the means of processing information for optimum accessibility and usability (Borko, 1968). Due to the close relationship between these two fields, especially the shared information perspective (Bates, 1999), it is very common to find that they are considered as one field with the combined name Library and Information Science (LIS). Among the many issues that must be addressed in LIS are open access to information; copyright protection, and at the same time, protection of citizens' right to access copyrighted information; appropriate security for information; individual privacy; and the cost of information access. Given these important and often competing interests, it becomes increasingly important that libraries, as institutions that often reflect the public interest rather than personal gain, play critical roles in influencing the policies that affect information dissemination (Rubin, 2000).

MIS is a field concerning both the management of information technology and the use of information technology for managerial and organizational purposes (http://www.misq. org). With the announcement of the coming of information technology in organizations (Leavitt \& Whisler, 1958), the original perspective of MIS centered on management, information, systems, or a combination of the three (Banville \& Landry, 1989). Davis defined MIS as "an integrated man/ machine system for providing information to support the operation, management, and decision making functions in an organization." (Davis, 1974) At the first International Conference on Information Systems (ICIS), Keen defined MIS as "the effective design, delivery, and use of information systems in organizations." (Keen, 1980) Baskerville and Myers (2002) broadly defined MIS as "the development, use and application of information systems by individuals, organizations and society," and they pointed out that MIS has gone through a steady shift from a techno-centric focus to a balanced view of technology, organizational, management, and social focus. Like many other interdisciplinary fields, MIS has gone through many debates on its identity, foci, and future development (Banville \& Landry, 1989; Benbasat \& Weber, 1996; Benbasat \& Zmud, 2003).

HCI is a scientific field focusing on how people interact with computers and how computers can be designed to interact with humans more successfully (Pfaffenberger, 2003). Among several different perspectives of HCI, ACM SIGCHI once defined it as a discipline concerned with the design, evaluation, and implementation of interactive computing systems for human use and with the study of major phenomena surrounding them (Hewett et al., 1992). More broadly, Preece et al. considered HCI as designing computer systems that support people so that they can carry out their activities productively and safely (Preece et al., 1994). Within the business, managerial, organizational, and cultural contexts, HCI studies are concerned with the ways humans interact with information, technologies, and tasks (Zhang et al., 2002).

All these three fields should qualify to be scientific fields (Banville \& Landry, 1989; Whitley, 1984): there are courses and degrees offered on all these subjects, identifiable communities with memberships that meet in annual conferences, and designated academic journals as outlets of scientific inquires. Historically, LIS, MIS, and HCI are distinctive fields with minimum overlaps on communities, conferences, and journals, although this is changing (see below). It is notable that some of them, such as HCI, may be a late comer in having a formal physical academic department or may not have one at all. We consider this to be very normal for inter- and multidisciplinary fields that normally do not start with a designated academic department but coexist or are integrated with other more traditional departments. This physical setting (or lack of), however, should not diminish the existence of a scientific field. For example, HCI has been around for more than 20 years (with its first official conference held in 1982); its official organization (ACM SIGCHI) has thousands of members; there are HCI degrees offered at all levels; the field has several highly prestigious academic journals of which its oldest journal, International Journal of Human-Computer Studies (formerly International Journal of Man-Machine Studies), has been around since 1968; and there are specialized HCI research streams such as HCI in the MIS field.

From the definitions and descriptions of these fields, one can also see a great deal of overlaps on the fundamental components and their relationships. All three fields are concerned with people, information, technology, and organization and society (broadly defined), and the interplay among these components. These fields also share many other characteristics (Bates, 1999; Grudin, 2005; Grudin, 2006a; Grudin, 2006b; Hjorland, 2000; Hjorland \& Albrechtsen, 1995; Zhang et al., 2002; Zhang \& Dillon, 2003; Zhang \& Li, 2005; Zhang, Nah, \& Preece, 2004). In recent years, researchers trained in one field conduct research that cuts across the other fields. For example, at the recent annual 
conference of ACM SIGCHI, the major HCI conference, scholars discussed what I-schools can offer for HCI research or, in other words, how can scholars physically situated in I-schools benefit for HCI type of research (Carroll et al., 2006). Similar to AIS, the global association for MIS scholars, the LIS community's association, ASIST (American Society for Information Science and Technology) has a special interest group on HCI. Two recent volumes of the Advances in Management Information Systems series contain 37 interdisciplinary studies by top scholars in MIS, Information, and HCI fields (Galletta \& Zhang, 2006; Zhang \& Galletta, 2006). All these evidences suggest that these fields are closely related to and starting to influence each other.

There are also distinctions among the three fields. For example, the nature of information as a fundamental component is different in these three fields. Although LIS is concerned with all types of recorded information produced by human agency, it is on the forms and structures of subject domain information (Bates, 1999). In other words, LIS is about representation (forms and structures) of information (in subject domains). The subject domains that are of interest to LIS can be any and all of human studies. Similarly, the application domains for LIS can be any of human activities. MIS and HCI, on the other hand, are concerned with the information that is produced, managed, and used by people in the application domains. For MIS, most application domains are business, managerial, and organizational related. For HCI, the application domains are much broader.
Although all four fundamental components are studied in each of the three fields, they are not equally emphasized. At a given time in history (that is, the following profiles of the fields change over time), one may find that MIS emphasizes more on the interplay between technology, people, and organization, which implies the information aspect (although there are studies focusing on information in particular, such as information representations, knowledge management, among others). LIS is more on information, people, and society while implying that information is supported by technology (we note that information system design is an important sub area of LIS too); HCI, heavily influenced by cognitive psychology, is more on technology, people, and information (again, society issues are also studied in $\mathrm{HCI}$ ).

In addition, each field may have a different emphasis on the abstract level of the organization or society component: MIS concerns working groups and institutions or formal organizations for this organization/society component but less so on larger societies (although this is changing in recent years due to globalization); LIS is less so on working groups, somewhat on institutes and somewhat on larger society; and HCI spans most levels.

Based on the I-model, Figure 2 demonstrates some of the commonalities and differences among the three fields as we just discussed above. Thicker links indicate stronger interactions and integrations of the fundamental components. Domains for each field are also indicated in the demonstrations.

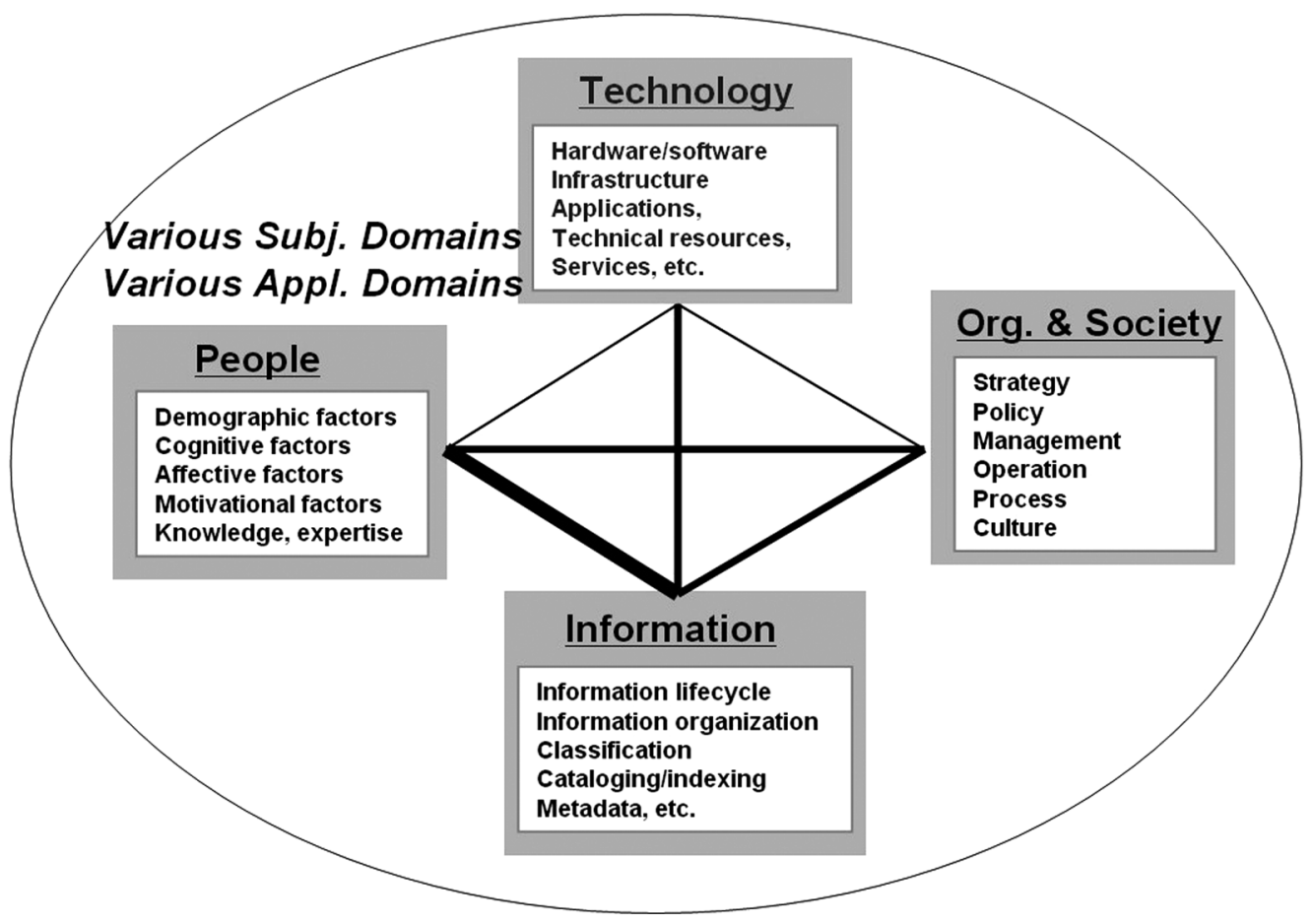

FIG 2a. Library and Information Science (LIS). 


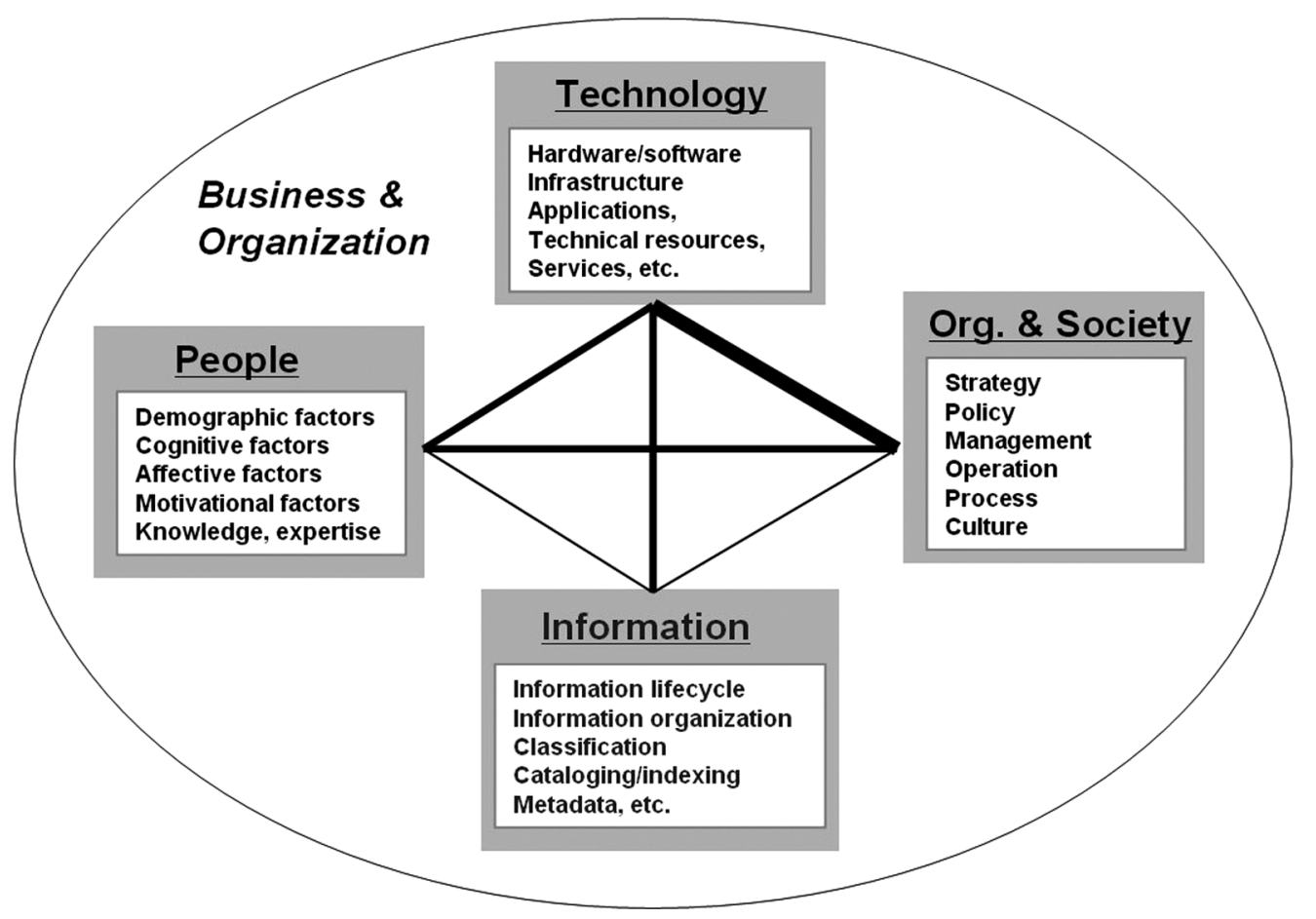

FIG 2b. Management Information Systems (MIS).

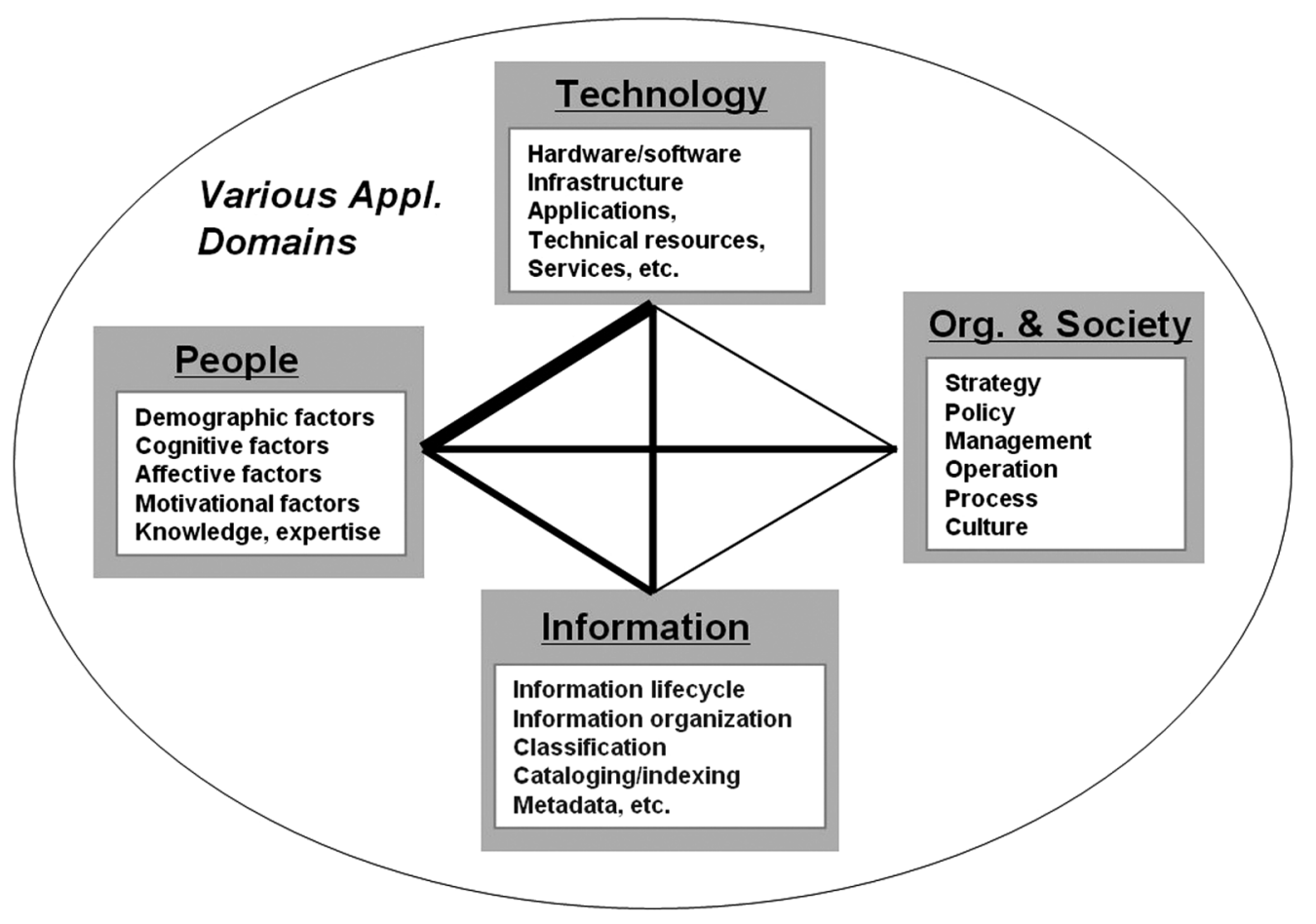

FIG 2c. Human-Computer Interaction (HCI).

It is noted that Figure 2 is a snapshot view of a field at a given time in its historical development. A particular field can be examined using the I-model across different development stages in its history. Such an examination can reveal the changes of emphases of the field over time, depicting an equilibrium portrait of the field where fundamental components adapt to each other in responding to changes in the fundamental components and external environments. For example, in early days of the library science field, technology played a small role and the energy of the field was more on the interaction between people and information. In the information era, the fast development of technology (changes in a fundamental 
component) pushes all other components to adapt, creating new research issues and concerns, thus new foci in research, education, and professional practice. When our nation is threatened by terrorists (a change in the external environment of a field), the emphasis of the field shifts and new research issues and educational programs are created (such as information assurance). A field, like other organisms, must have the ability to adapt and evolve in order to "survive."

One interesting observation from the above demonstration is that a researcher may look at a field in light of the I-Model perspective that may be different from but complement to other perspectives. For example, in Figure 2b, the MIS field is captured by the four fundamental components and their dynamic interaction and integration. The whole of this capture can be considered an "information system"- a commonly referenced concept that involves people, information, technology, procedures, policies, strategies, management, and so on-that evolves over time, and that requires coordination, communication, and collaboration of all components involved. In other words, the concept of "information system" becomes more explicit and concrete within the I-Model framework. The same can be examined in other fields such as LIS and HCI.

\section{The Information Field as Described by the I-Model}

The motive of this study was to attempt to address the following questions: What is the I-field? What are the similarities and differences between the I-field and other information related fields? What are the aspects that make them similar or related to each other? What are the fundamental elements of concerns and issues of the I-field? What potential directions can the I-field take for research efforts, education missions, and practice? What opportunities can the I-field have for collaborations with other related fields? These questions can be answered with the help of the I-model. It is noted that like many emerging fields, there can be many definitions, perspectives, and comprehensions of the I-field. Here, we present ours that are anchored to other information related fields and are structured with the I-model as a theoretical framework.

The I-field contains four fundamental components, with various interactions, integrations, and adaptations of the fundamental components to internal and external changes. The subject domains of interest can be any human studies, and the application domains can be of any human activities. The concept of information includes any information that is created by human agency and has social purposes. Figure 3 roughly depicts the I-field as we just described.

By this definition, I-field is very broad. On one hand, it can be described as either building on or including existing information related fields such as LIS, MIS, HCI, and others. On the other hand, it can be described as complementing existing information related fields to explore un-explored opportunities. The uniqueness of the I-field is its holistic and consistent perspective of socially purposeful information with technology support, and any phenomena surrounding it. From this perspective, a broader range of studies that would not have been thought of as information related can now fit the I-field once the information perspective is applied. This can include fields such as policy and regulation, publication administration, politics, sociology, communication, organization and industry psychology, among other social sciences.

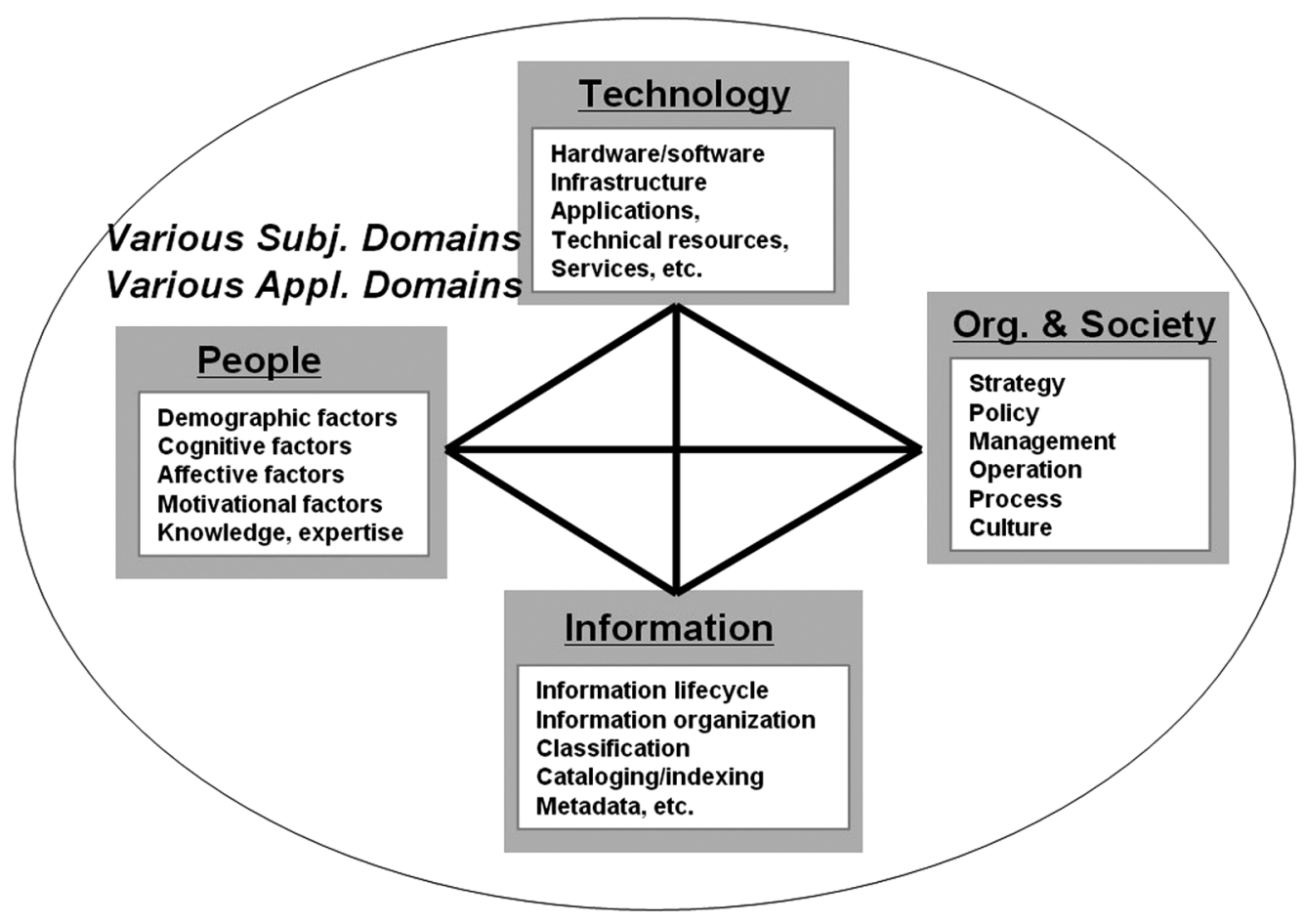

FIG 3. The information field and its characteristics. 


\section{Conclusion}

Studying an emerging discipline is a difficult task. The main objective of this article is to introduce the I-model as a theoretical framework for identifying the information field and to point out potential issues and opportunities. One way of identifying the I-field is to demonstrate the similarities and differences between the I-field and several other information related fields. The I-model seems to be able to illustrate the connections the I-field has with the other fields, such as MIS, LIS, and HCI. We posit that all information related fields, including the I-field, are built on a number of other fields with their own unique foci and concerns. That is, core components from other fundamental fields interact and integrate with each other to form dynamic and interesting information related fields that all have to do with information, technology, people, and organization or society in various domains and contexts. The I-model seems also to be able to prescribe potential issues and opportunities for information related fields. Thus it is a possible tool to study the emerging information field and to demonstrate the similarities and differences among information related fields.

We have given examples of several potential uses of the I-model. Besides providing a unified framework of these related fields, it can be used to examine case studies, research projects, educational programs, and curricula concerns. The framework can be especially useful for prescribing new academic departments, education programs, and curricula designs. Additional extensive applications of the I-model to these uses are beyond the scope of this article. There are, however, expectations that the I-model may be of great use for further analyzing more disciplines, especially social science disciplines in which information plays an important role. For example, we expect that the I-model can be used to describe some of the characteristics of educational research (studies on teaching and learning human knowledge), communication studies (processes of sharing information and related phenomena), and journalism (discovery and transmission of news or information), among others. We expect that the I-model can prescribe new educational programs that fit the needs of the societies. We also expect that the I-model can be applied to entail specific research programs within an information related field, such as information retrieval and information architecture in LIS, thus provide directions and opportunities to advance research in the information related fields. As we demonstrate in the article, the I-model is expected to be a research tool for opening up research issues, difficulties and opportunities, thus inviting further investigative research efforts on seeming established research topics. Overall, we hope that our work here will inspire more efforts on exploring the foundations of the information related fields and their prospective future directions.

\section{Acknowledgments}

The authors are grateful to Drs. Gary Dickson, Robert Heckman, Noam Tractinsky, and Barbara Kwasnik for providing comments and suggestions on early drafts. They thank the anonymous reviewers for their constructive comments during the review process. The earliest ideas of the I-model were presented at the First Conference of the I-School Community, Penn State University, September 2005.

\section{References}

Agarwal, R., \& Karahanna, E. (2000). Time flies when you're having fun: Cognitive absorption and beliefs about information technology usage. MIS Quarterly, 24(4), 665-694.

Allen, R. (2000). The Penguin English Dictionary: Penguin Books.

Banville, C., \& Landry, M. (1989). Can the field of MIS be disciplined? Communications of the ACM, 32(1), 48-60.

Baskerville, R.L., \& Myers, M.D. (2002). Information systems as a reference discipline. MIS Quarterly, 26(1), 1-14.

Bates, M.J. (1998). Indexing and access for digital libraries and the Internet: Human, database, and domain factors. Journal of the American Society for Information Science, 49(13), 1185-1205.

Bates, M.J. (1999). The invisible substrate of information science. Journal of the American Society for Information Science, 50(12), 1043-1050.

Benbasat, I., \& Weber, R. (1996). Rethinking "diversity" in information systems research. Information Systems Research, 7(4), 389-399.

Benbasat, I., \& Zmud, R. W. (2003). The identity crisis within the IS discipline: Defining and communicating the discipline's core properties. MIS Quarterly, 27(2), 183-194.

Benjamin, R. (1971). Benjamin, control of the information systems development cycle. New York: Wiley.

Benjamin, R., \& Eriksson, I. (2001). Dilemmas for managers: Unintended consequences of information and communications technologies. In G. Dickson \& G. DeSanctis (Eds.), Information technology and the future enterprise: Prentice Hall.

Benjamin, R.I., \& Levinson, E. (1993). A sramework for managing ITenabled change. Sloan Management Review, 34(4), 23-33.

Blackman, B., Bublotz, D., Foster, C., Schmidt, J., Bates, M., Sutton, S., et al. (1995). Future directions for the library profession and its education: CLA task force on the Future of Librarianship.

Borko, H. (1968). Information science: What is it? Journal of the American Society for Information Science, 19, 3-5.

Brown, J.S., \& Duguid, P. (2001). Don't count society out. In P. Denning (Ed.), The invisible future: The seamless integration of technology into everyday life (pp. 117-144). New York: McGraw Hill.

Carroll, J.M., Dourish, P., Friedman, B., Kurosu, M., Olson, G., \& Sutcliffe, A. (2006, April 22-27). Institutionalizing HCI: What do I-schools offer? Paper presented at the ACM CHI Annual Conference, Montreal, Quebec, Canada.

Chandler, A. (1977). The ACM visible hand: The managerial revolution in American business: Harvard University Press.

Crystal, D. (2001). The Crystal Reference Encyclopedia: Quotations Ltd. Davis, G. (1974). Management information systems: conceptual foundations, structure, and development. New York: McGraw-Hill.

Dervin, B. (1997). Given a context by any other name: Methodological tools for taming the unruly beast. In P. Vakkari, R. Savolainen, \& B. Dervin (Eds.), Information seeking in context, Proceedings of an international conference on research information needs, seeking and use in different contexts (pp. 13-38). Tampere, Finland: Taylor Graham.

Dickson, G., \& DeSanctis, G. (2001). Information technology and the future enterprise: Prentice Hall.

Ellis, D., Allen, D., \& Wilson, T. (1999). Information science and information systems: Conjunct subjects disjunct disciplines. Journal of the American Society for Information Science, 50(12), 1095-1107.

Floridi, L. (2005). Semantic conceptions of information. http://plato.stanford.edu/entries/information-semantic/

Friedman, T. (2005). The world is flat: A brief history of the twenty-first century: Farrar, Straus and Giroux.

Galletta, D., \& Zhang, P. (Eds.). (2006). Human-computer interaction and management information systems-applications (Vol. 5). Armonk, NY: M. E. Sharpe, Inc. 
Grudin, J. (2005). Three faces of human-computer interaction. IEEE Annals of the History of Computing, 27(4), 46-62.

Grudin, J. (2006a). Human factors, CHI and MIS. In P. Zhang \& D. Galletta (Eds.), Human-computer interaction and management information systems: Foundations (Vol. 1, pp. 402-421). Armonk, NY: M.E. Sharpe.

Grudin, J. (2006b). Is HCI homeless? In search of inter-disciplinary status. Interactions: New Visions of Human-Computer Interaction, 13(1), 54-59.

Hewett, T., Baecker, R., Card, S., Carey, T., Gasen, J., Mantei, M., et al. (1992). ACM SIHCHI curricula for human-computer interaction. New York: Association for Computing Machinery.

Hjorland, B. (2000). Library and information science: practice, theory and philosophical basis. Information Processing and Management, 36, 501-531.

Hjorland, B., \& Albrechtsen, H. (1995). Toward a new horizon in information science: Domain analysis. Journal of the American Society for Information Science, 46(6), 400-425.

Joy, W. (2000). Why the future doesn't need us. Issue 8.08, April Wired Magazine http://www.wired.com/wired/archive/8.04/joy_pr.html. Last accessed June 28, 2007.

Keen, P.G.W. (1980). MIS research: Reference disciplines and a cumulative tradition. Paper presented at the The First International Conference on Information Systems.

Kegan, R., \& Lahey, L.L. (2000). How the way we talk can change the way we work: Seven languages for transformation: Jossey-Bass.

Larson, R. (2004, October 19-22). Reinforcing the "I" in IT education. Paper presented at the Educause.

Larson, R. (2005). I-school for the 21st century: An introduction to the School of Information Sciences at the University of Pittsburgh.

Leavitt, H.J., \& Whisler, T.L. (1958). Management in the 1990s. Harvard Business Review, 41-48.

Linstone, H.A. (1985). Multiple perspectives: Overcoming the weaknesses of MS/OR. Interfaces, 15(4), 77-85.

Liu, X., Benjamin, R., \& Zhang, P. (2007). Examining IT enabled change cases with a model of the information field: The Tiger Creek Case. Paper presented at the Hawaii International Conference on System Sciences (HICSS), IEEE.

Markus, L.M. (2003). Technochange management: Using IT to drive organizational change. Journal of Information Technology, 1-19.

Markus, M.L., \& Benjamin, R. (1997). The magic bullet theory in IT-enabled transformation. Sloan Management Review, 55-68.

Nardi, B.A., \& O’Day, V.L. (1999). Information ecologies: using technology with heart: The MIT Press.

Osterlund, C.S. (2000). The power of whiteboards: Boundary objects and the politics of coordination and knowledge sharing. Paper presented at the OCIS/OMT Symposium, The Academy of Management, Toronto.

Pfaffenberger, B. (2003). Webster's New World ${ }^{\mathrm{TM}}$ Computer Dictionary (Vol. Wiley Publishing, Inc.). Indianapolis, Indiana.

Preece, J., Rogers, Y., Sharp, H., Benyon, D., Holland, S., \& Carey, T. (1994). Human-computer interaction Reading, MA: Addison-Wesley.

Rubin, R.E. (2000). Foundations of library and information science. New York: Neal-Schuman.

Schein, E.H. (1993). How can organizations learn faster: The challenge of entering the green room. Sloan Management Review, 88-89.

Schein, E.H. (1996). Kurt Lewin's change theory in the field and in the classroom: Notes toward a model of managed learning. Systemic Practice and Action Research 9(1).

Scott Morton, M.S. (Ed.). (1991). The corporation of the 1990s: Information technology and organizational transformation. New York: Oxford University Press.

Shannon, C.E. (1948). A mathematical theory of communication. Bell System Technical Journal, 27, 379-423 \& 623-656.

Stanton, J.M., \& Stam, K. R. (2006). The visible employee. Medford, NJ: Information Today.

Weaver, W. (1949). The mathematics of communication. Scientific American, 181(1), 11-15.

Weiner, N. (1961). Cybernetics (2nd ed.). Cambridge, MA: The MIT Press.
Whitley, R. (1984). The intellectual and social organization of the sciences. Oxford: Clarendon press.

Wood-Harper, T., \& Wood, B. (2005). Multiview as social informatics in action: past, present and future. Information Technology \& People, 18(1), 26-32.

Zhang, P., Benbasat, I., Carey, J., Davis, F., Galletta, D., \& Strong, D. (2002). Human-computer interaction research in the mis discipline. Communications of the Association for Information Systems, 9(20), 334-355.

Zhang, P., \& Dillon, A. (2003). HCI and MIS: Shared concerns. International Journal of Human-Computer Studies, 59(4), 397-402.

Zhang, P., \& Galletta, D. (Eds.). (2006). Human-computer interaction and management information systems-Foundations (Vol. 4). Armonk, NY: M. E. Sharpe, Inc.

Zhang, P., \& Li, N. (2005). The intellectual development of Human-Computer Interaction research: A critical assessment of the MIS literature (1990-2002). Journal of Association for Information Systems, 6(11), 227-292.

Zhang, P., Li, N., \& Sun, H. (2006, January 4-7). Affective quality and cognitive absorption: Extending technology acceptance research. Paper presented at the Hawaii International Conference on System Sciences (HICSS), Kauai, Hawaii, IEEE.

Zhang, P., Nah, F.-H. F., \& Preece, J. (2004). HCI studies in MIS. Behaviour \& information technology, 23(3), 147-151.

Zuboff, S. (1989). In the age of the smart machine: The future of work and power. New York: Basic Books.

Zuboff, S., \& Bronsema, G. (1984). Expense tracking system at Tiger Creek. Harvard Business School Cases.

\section{Appendix}

\section{A List of the Information Schools}

This list represents the participating I-schools at The First Conference of the I-School Community: Bridging Disciplines to Confront Grand Challenges, College Park, Pennsylvania, September 28-30, 2005 (http://iconference.ist.psu.edu/).

- University of California, Berkeley, School of Information Management and Systems

- University of California, Irvine, The Don Bren School of Information and Computer Sciences

- University of California, Los Angeles, Graduate School of Education and Information Studies

- Drexel University, College of Information Science and Technology

- Florida State University, College of Information

- Georgia Institute of Technology, College of Computing

- University of Illinois Urbana-Champaign, The Graduate School of Library and Information Science

- Indiana University, School of Informatics

- Indiana University, School of Library and Information Science

- University of Maryland, College of Information Studies

- University of Michigan, The School of Information

- University of North Carolina, School of Information and Library Science

- The Pennsylvania State University, School of Information Sciences and Technology

- University of Pittsburgh, School of Information Sciences

- Rutgers, the State University of New Jersey, School of Communication, Information, and Library Studies

- Syracuse University, School of Information Studies

- University of Texas, Austin, School of Information

- University of Toronto, Faculty of Information Studies

- University of Washington, Information School 